\title{
A wavelet melt detection algorithm applied to enhanced-resolution scatterometer data over Antarctica (2000-2009)
}

\author{
N. Steiner and M. Tedesco \\ The City College of New York at the City University of New York, New York, USA \\ Correspondence to: N. Steiner (nsteiner@ccny.cuny.edu) \\ Received: 4 May 2013 - Published in The Cryosphere Discuss.: 14 June 2013 \\ Revised: 11 November 2013 - Accepted: 13 November 2013 - Published: 7 January 2014
}

\begin{abstract}
Melting is mapped over Antarctica at a high spatial resolution using a novel melt detection algorithm based on wavelets and multiscale analysis. The method is applied to $\mathrm{Ku}$-band $(13.4 \mathrm{GHz})$ normalized backscattering measured by SeaWinds onboard the satellite QuikSCAT and spatially enhanced on a $5 \mathrm{~km}$ grid over the operational life of the sensor (1999-2009). Wavelet-based estimates of melt spatial extent and duration are compared with those obtained by means of threshold-based detection methods, where melting is detected when the measured backscattering is $3 \mathrm{~dB}$ below the preceding winter mean value. Results from both methods are assessed by means of automatic weather station (AWS) air surface temperature records. The yearly melting index, the product of melted area and melting duration, found using a fixed threshold and wavelet-based melt algorithm are found to have a relative difference within $7 \%$ for all years. Most of the difference between melting records determined from QuikSCAT is related to short-duration backscatter changes identified as melting using the threshold methodology but not the wavelet-based method. The ability to classify melting based on relative persistence is a critical aspect of the wavelet-based algorithm. Compared with AWS airtemperature records, both methods show a relative agreement to within $10 \%$ based on estimated melt conditions, although the fixed threshold generally finds a greater agreement with AWS. Melting maps obtained with the wavelet-based approach are also compared with those obtained from spaceborne brightness temperatures recorded by the Special Sensor Microwave/Image (SSM/I). With respect to passive microwave records, we find a higher degree of agreement $(9 \%$ relative difference) for the melting index using the waveletbased approach than threshold-based methods (11\% relative difference).
\end{abstract}

\section{Introduction}

The future response of the Antarctic Ice Sheet to a changing climate is one of the largest uncertainties in the estimates and predictions of global sea-level rise over the coming decades (Hughes, 1981; Joughin and Alley, 2011; Overpeck et al., 2006; Shepherd and Wingham, 2007; Bromwich and Nicolas, 2010; Dowdeswell, 2006; Lemke et al., 2007). As temperature increases at high latitudes (e.g., Comiso, 2010; Hansen et al., 2010) the rate of surface melting is expected to increase (Ohmura, 2001). Analysis of long-term trends in weather station air temperatures indicates a strongly positive trend in the duration of melting conditions over the Antarctic Peninsula (Vaughn, 2006; Barrand et al., 2013). Efforts to quantify mass balance indicate a positive trend in mass loss for much of the West Antarctic Ice Sheet and the Antarctic Peninsula but a negative trend for much of the East Antarctic Ice Sheet (e.g., Chen et al., 2011; Rignot and Thomas, 2002; Shepherd and Wingham, 2007; Rignot et al., 2011). Recent results using a combined climate modeling and satellite observational approach suggest that in the period 1992 through 2011, the East Antarctic Ice Sheet gains mass at a rate of $14 \pm 43 \mathrm{Gt} \mathrm{yr}^{-1}$, while the West Antarctic Ice Sheet and the Antarctic Peninsula exhibit a mass loss of $-65 \pm 26$, and $-20 \pm 14 \mathrm{Gt} \mathrm{yr}^{-1}$, respectively (Shepherd et al., 2012).

In the recent past, the Antarctic Peninsula has experienced episodes of dramatic ice-shelf break-up, for example the 2002 Larsen B Ice Shelf and the 2008 Wilkins Ice Shelf collapses. Both were the consequence of a suite of physical surface processes as well as ocean-ice-shelf interaction mechanisms, but with surface melting likely playing a key role. Indeed, the formation of meltwater ponds on the surface of the ice shelves caused by the accumulation of runoff might have 
contributed to the process of disintegration through hydrofracturing (e.g., MacAyeal et al., 2003; Scambos et al., 2009). Instability caused by ice-shelf loss has been shown to increase observed ice flow velocity in related glacial tributaries (Rignot et al., 2004; Scambos et al., 2004; Rott et al., 2011). Melting also drives firn densification and compaction (Holland et al., 2011).

Direct measurements of melting are not available from in situ data. Additionally, quantities necessary to fully solve the surface energy balance are often unavailable. Therefore, surface melting is generally estimated from near-surface air temperature measurements performed by automatic weather stations (AWS) when and where available. Such measurements are sparse over Antarctica and mostly performed around coastal areas and at low elevations. Moreover, data measured from AWS represent only local conditions and are difficult to extrapolate or estimate melting with at large spatial scales without adding biases or increasing uncertainty.

Active and passive microwave spaceborne instruments are used to monitor melting over snow-covered areas due to the insensitivity to atmospheric and illumination conditions and high sensitivity to liquid water (e.g., Abdalati and Steffen, 2001; Ashcraft and Long, 2006; Liu et al., 2005; Mote et al., 1993; Nghiem et al., 2001, 2007; Steffen et al., 2004; Tedesco et al., 2007; Torinesi et al., 2003; Wang et al., 2008). For vegetation-free snow-covered areas, the volume scatter component will be dominant for radar backscatter measurements at Ku-band frequencies (Ulaby et al., 1982). Backscatter loss due to the presence of liquid water in snow during melting is responsible for a rapid and considerable decrease in the Ku-band normalized microwave backscatter, $\sigma^{0}$, with respect to dry snow conditions. This is because of the increased imaginary component in the bulk complex dielectric constant of wet snow relative to dry snow (e.g., Ngheim et al., 2001; Stiles and Ulaby, 1980). This same emissivity change will create near-blackbody emission characteristics for wet snowpacks leading to a marked increase in brightness temperatures (Ulaby et al., 1982; Stiles and Ulaby, 1980).

Various melt detection algorithms have been developed and applied to active microwave time series to estimate seasonal melt. Often, a threshold value of absolute magnitude signal change either constant or regionally variable is used to detect melt-related changes. (e.g., Ashcraft and Long, 2006; Trusel et al., 2012; Wang et al., 2008; Zwally and Fiegles, 1994). Generally, this threshold value is chosen as an approximation of the expected microwave response during snowmelt with respect to a baseline referring to wintertime dry snow conditions (e.g., Ashcraft and Long, 2006). We refer to all methods that consider a constant value threshold in the following as fixed-threshold approaches. In contrast, approaches employing physically based temporally or spatially variable threshold values will be referred to as dynamic threshold approaches (Mote and Anderson, 1995; Tedesco, 2009). Algorithms that rely on the intrinsic properties of a measurement within time series have also been applied to snowmelt detection (Joshi et al., 2001; Liu et al., 2005; Wang and $\mathrm{Yu}, 2011$ ). These approaches are dynamic in that they are based on the magnitude of relative change within each individual time series. A dynamic approach assumes that large changes in the microwave region are associated with melting events so that "edges" are created in the backscattering time series. These edges can be identified and used to estimate the timing of melting events. Edge-detection algorithms of this type have been developed using derivative-of-Gaussian, (e.g., Joshi et al., 2001) or multiscale wavelet edge detection (Liu et al., 2005).

Building on previous dynamic melt detection approaches (Joshi et al., 2001; Liu et al., 2005), we introduce a waveletbased melt detection algorithm based on multiscale analysis of wavelet transforms to identify melting events using singularity detection (Mallat and Hwang, 1992). Such method identifies points of substantial transition in backscatter time series using no a priori information. In addition to this, a measure of the signal regularity at the point of transition can classify the transition "type", which allows the separation of persistent melting events (melting lasting continuously for a certain number of days) from transient or sporadic melting events. Besides the wavelet-based approach, we also consider a fixed-threshold algorithm-derived melting record from the same data set. This fixed-threshold record is to evaluate the wavelet-based method where alternative validation data, such as in situ weather-station measurements, are not available. The fixed-threshold method is performed as in Ashcraft and Long (2006) and Barrand et al. (2013). All results of the current dynamic algorithm are shown relative to this fixedthreshold algorithm approach.

We apply these two melt detection algorithms to an enhanced spatial resolution QuikSCAT (Ku band) scatterometer data set distributed by the Microwave Earth Remote Sensing (MERS) Laboratory with an effective resolution of $5 \mathrm{~km}$ gridded to $2.225 \mathrm{~km}$ (Early and Long, 2001; Spencer et al., 2000). The enhanced spatial resolution allows for the discrimination of melting patterns at sub-ice-shelf resolution and resolves melting patterns and trends that are not apparent in coarse-spatial-resolution products. Highresolution data sets are ideal for the Antarctic Peninsula, a region of high elevation contrast where the coarse resolution of some microwave observations may underestimate melt due to a large sub-pixel elevation gradient. We focus on melt onset date, melt-off date, melt extent and melt duration for the whole Antarctic continent. Results from both dynamic wavelet-based and fixed-threshold approaches applied to the enhanced-resolution QuikSCAT data record are also compared with those obtained from spaceborne microwave brightness temperatures from the Special Sensor Microwave/Imager (SSM/I) and melt estimates obtained from the analysis of surface air-temperature values recorded by automated weather stations. 


\section{Methodology}

A general overview of wavelets and the specific methodology applied here is presented in Sect. 2.1. This is followed by a more detailed discussion of the mathematics and examples of wavelet melt detection in Sect. 2.2. An overview of the processing steps and operation of the melt detection algorithm is presented in Sect. 2.3.

\subsection{Melt detection using wavelets}

The duration of seasonal melting over Antarctica is estimated by means of a wavelet analysis. A wavelet transform unfolds a one-dimensional time series of $\sigma^{0}$ into a twodimensional power spectrum of position and scale (i.e., inverse frequency). The wavelet transform can evaluate localized variability of a backscatter time series using a series of convolutions with a dilating and translating wave-like function (Daubechies, 1992). In this study, we use the wavelet transform as a differential operator, in that it is able to approximate the derivative of a smoothed data series at each time location. Melting and refreezing events will cause large variations in $\sigma^{0}$ and therefore appear as local maxima or minima in the wavelet transform.

Many studies in the natural sciences have used the wavelet transform to detect changes in one-dimensional time series, for example the detection of tropical convection anomalies (Weng and Lau, 1994) and geomagnetic jerks (Alexandrescu et al., 1995). Wavelet analysis methods have also been applied to snowmelt detection: specifically, Liu et al. (2005) apply a wavelet-based methodology to identify large changes in measured brightness temperature values associated with melting events over Antarctica.

We apply an approach similar to Liu et al. (2005), but with several key differences. First, we apply this approach to active microwave (Ku band, $13.4 \mathrm{GHz}$ ) measurements. Additionally, we use no a priori information, such as statistical or physically based thresholding of wavelet coefficients, for any of the pixel locations. Melt and refreezing events are both identified and classified in the framework of singularity detection as introduced Mallat and Hwang (1992). Continuous wavelet transforms are used to detect melting events that appear as discontinuous events in the backscatter time series and to eliminate those melting events that are determined to be sporadic in time using multiscale analysis (Mallat and Hwang, 1992; Mallat, 1999; Alexandrescu, 1995). This methodology is novel, and to our knowledge, it is the first time that such an approach has been applied to remote sensing of snow and ice.

\subsection{Continuous wavelet transform and multiscale analysis}

The continuous wavelet transform (CWT) of the seasonal (June of one year through May of the successive year) backscatter, $\sigma^{0}(t)$ is defined by the convolution product

$W \sigma^{0}(u, s)=\int_{-\infty}^{+\infty} \sigma^{0}(t) \frac{1}{\sqrt{s}} \psi\left(\frac{t-u}{s}\right) \mathrm{d} t=\left(\psi_{s}^{*} \sigma^{0}\right)(u)$,

where $\psi$ is the wavelet function, $u$ is the translation parameter, $s$ is the scaling factor and ${ }^{*}$ is the convolution operator (Mallat, 1999). The analyzing wavelet, $\psi$, is a real-valued, localized zero-mean function with a vanishing integral (e.g., the integral of $\psi$ is zero) (Mallat, 1999; Holschneider, 1995). The analyzing wavelet function used in this study is defined using the first derivative of a Gaussian function:

$\psi(t)=(-1)^{n} \frac{\mathrm{d}^{n} \theta(t)}{\mathrm{d} t^{n}}$

and

$\theta(t)=\frac{1}{\sqrt{2 \pi}} \exp \left(-\frac{t^{2}}{2}\right)$,

with order $n=1$ (Mallat, 1999).

A wavelet function with a Gaussian base is necessary to ensure that wavelet coefficient maxima will be continuous from large to small scales (Mallat, 1999). This allows for the tracing and association of wavelet maxima across scales, a process that is key for multiscale analysis. As an example, a microwave backscattering time series recorded over the Larsen Ice Shelf AWS during the 2006-2007 season is plotted in Fig. 1a, with the corresponding CWT plotted in Fig. 1b. The magnitude of local maxima or minima in $W \sigma^{0}$ (black and white areas, respectively) are correlated with the magnitude of backscatter change (Liu et al., 2005). This is expected as $\psi$ is equivalent to the first derivative of a smoothing function as indicated in Eqs. (2) and (3). In Fig. 1b the conical field of negative $W \sigma^{0}$ intercepts the scale axis at its narrowest width at a position $(u=185)$ coincident with a $\sim 20 \mathrm{~dB}$ decrease in $\sigma^{0}$ over several days. Fields of elevated $W \sigma^{0}$ in a CWT, or "cones of influence" (Mallat, 1999), are located where the data in the time series (or its derivative) behave as a discontinuous function (Mallat and Hwang, 1992; Holschneider, 1995; Mallat, 1999). Melting or refreezing events therefore create cones of influences that will converge at fine scales to the position of signal discontinuity (Mallat and Hwang, 1992; Mallat, 1999; Liu et al., 2005). We refer to these positions as singularities (e.g., Mallat and Hwang, 1992).

The values contained in a cone of influence compose the scalar components (the signal change relative to the temporal scale) of that transition and are used in multiscale analysis. We define the set of all CWT coefficient maxima along the "ridge" of the maxima cone as the wavelet transform modulus maxima line (WTMML) for each singularity. These positions are found where $(\delta \backslash \delta u) W \sigma^{0}(u, s)=0$ and are connected across adjacent scales from large duration to small (Hermann, 2001; Mallat, 1999; Mallat and Hwang, 1992; Alexandrescu, 1995). The CWT, although redundant in its 

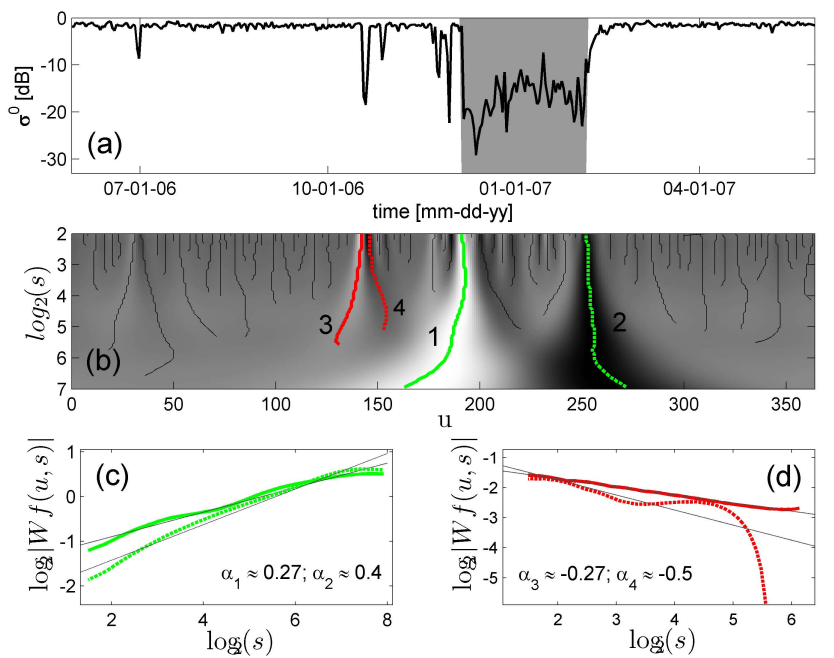

Fig. 1. (a) QuikSCAT $\sigma^{0}$ time series with the melt duration (MD) estimated using the CWT method shaded in grey. (b) The CWT of the time series in Fig. 1a, where dark-grey to black values indicate positive $W \sigma^{0}$ and light-grey to white values negative $W \sigma^{0}$. WTMMLs are indicated as black, green or red lines associated with melt onset (MO, WTMML 1) melt refreeze (MF, WTMML 2) and sporadic, early season melt (WTMML 3, WTMML 4). (c) The $W \sigma^{0}$ along WTMML plotted over all scales, $(s)$, and the associated $\alpha$ for the MO and MF events. (d) Same as Fig. 1c but for an early season sporadic melting.

frequency or scale representation of any signal, is necessary in this application as these positions are not easily connected if determined only at discrete dyadic scales (e.g., Liu et al., 2005). Additionally, tracing CWT maxima to the finest temporal scale ensures the accurate localization of melting events as these positions will be shifted with increasing scale, as evident in Fig. 1b.

The WTMML is then used to characterize the nature of $\sigma^{0}$ change at each singularity using multiscale analysis (e.g., Mallat and Zhong, 1992; Le Gondidec et al., 2002). The WTMMLs for several singularities in $\sigma^{0}$ are highlighted in Fig. $1 \mathrm{~b}$ and are labeled 1 through 4 . The apparent regularity of a $\sigma^{0}$ time series in the immediate neighborhood of each singularity can be estimated from the wavelet coefficient values that compose each WTMML (e.g., Mallat, 1999). The Holder exponent, $a$, is a measure of estimated regularity at the terminating position of each WTMML (Mallat and Zhong, 1992). An estimate of $a$ is found as (Mallat, 1999)

$\left|W \sigma^{0}(u, s)\right| \leq A e^{a}$

so that

$\ln \left|W \sigma^{0}(u, s)\right| \leq a \ln a+\ln A$.

Here, $\left|W \sigma^{0}\right|$ correspond to the wavelet coefficients that compose the WTMML. Using Eq. (4) and Eq. (5), $a$ as well as the coefficient $A$ are determined using a linear least-squares regression.

Each WTMML can be then classified by $a$ using several theoretical transition types whose $a$ value is known. For example, a step-like or Heaviside function will result in a near O a (Le Gonidec et al., 2002), while a ramp-like or smoothed transition has $a$ of 1 or greater (Mallat, 1999; Le Gonidec et al., 2002). For wet snow detection, we assume melt onset transitions (e.g., similar to $u=185$ in Fig. 1b) can be approximated by either a step-like or smoothed transition. Here the corresponding value of $a$ is $a_{1}=0.27$. Due to the complex nature of a time series, $a$ values determined by Eq. (5) are not expected to match the theoretical case since nearby singularities will have contributions to the WTMML (i.e., cones of influence will overlap if transitions are close in time) (Mallat, 1999). In Fig. 1a we observe a more gradual (smoothed) $\sigma^{0}$ transition, coincident with a refreezing event near $u=250$, where the determined regularity $\left(a_{2}=0.4\right.$, Fig. $\left.1 \mathrm{c}\right)$.

Spike-like or cusp-like transitions will produce negative $a$ in multiscale analysis (Le Gonidec et al., 2002; Mallat, 1999). In Fig. 1a, a $\sigma^{0}$ fluctuation, corresponding to position $u=140$ in Fig. 1b illustrates a transition that is sporadic in time. This transition produces two WTMMLs, shown in Fig. 1d, labeled 3 and 4, having negative and positive $\mathrm{W} \sigma^{0}$ components, respectively. From Eq. (2) it is determined that both can be approximated with negative $a$ values $\left(a_{3}=\sim-0.27, a_{4}=\sim-0.4\right)$. Negative $a$ values associated with a WTMML indicate the signal is both discontinuous and non-differentiable at that position, here $u=140$ (Mallat and Hwang, 1992). In terms of melt detection, by removing all negative $a$ transitions, we eliminate sporadic $\sigma^{0}$ changes that return to "dry" conditions rapidly relative to the reference scale. This creates a melt detection process that eliminates sporadic melting events.

For locations that do not experience melting events, changes in backscatter associated with snow properties changes are of low magnitude compared to changes in liquid water content, but produce positive $a$ in multiscale analysis. To reduce the influence of falsely classified melting events, we set a minimum threshold for $\left|\mathrm{W} \sigma^{0}\right|$ at each temporal scale along the WTMML corresponding to one order of magnitude $(10 \times)$ greater than that observed during winter (June, July and August). This is a conservative threshold and this choice does not appear to influence classification for areas experiencing melt.

\subsection{Melt detection process}

The WTMMLs from each backscattering time series are evaluated as a possible melting event according to the following criteria:

1. The WTMML must have a scale component that extends above a set minimum scale. Signal noise and noisy transition in backscatter produce WTMMLs 
only at small scales (i.e., high frequency). We set the minimum scale at $2^{5}$. We observed that using a scale of $2^{3}$ similar to Liu et al. (2005) could not eliminate all noisy transitions during the melting season. This increased minimum scale relative to previous studies is expected since the enhanced-resolution remote sensing product used in this study is noisier than the coarser resolution one (Ashcraft and Long, 2006; Spencer et al., 2000).

2. All $\left|\mathrm{W} \sigma^{0}\right|$ along the WTMML must have a value one order of magnitude $(10 \times)$ greater than those measured during the winter season. For areas experiencing melt, this condition does not have a large effect, since $\left|\mathrm{W} \sigma^{0}\right|$ produced at all scales for $\mathrm{a} \sim 3 \mathrm{~dB}$ transition in backscatter is many orders of magnitude greater than observed wintertime conditions. However, areas that experience snow property changes but no seasonal melt will produce WTMMLs with large scalar components since these changes are not "noisy" transitions and are temporally sustained. Since changes in LWC produce greater differences in backscattering values compared to snow property changes over a relatively short period (Stiles and Ulaby, 1980), we set the threshold with the $\left|\mathrm{W} \sigma^{0}\right|$ values of a WTMML, at all spatial scales, with a value an order of magnitude $(10 \times)$ greater than observed wintertime conditions.

3. The Holder exponent, $\alpha$, of each WTMML must be equal to or greater than zero. For reasons discussed in the previous section, we eliminate spike-like transitions in backscatter using a test of point-wise signal regularity.

All signal transitions that meet the three criteria above are considered to be either melt onset or refreeze events. To define periods of melt we select the WTMML that extends to the largest scales that has the greatest mean $\left|W \sigma^{0}\right|$. This transition is matched with a WTMML greatest mean $\left|W \sigma^{0}\right|$ in the set of transitions of opposite magnitude. This defines one seasonal melting event. We assume that refreeze must follow melting. This process is repeated with the remaining meltrelated WTMMLs to define additional periods of melting or periods of sustained refreeze within melting. The melt onset (MO) is defined as the first day of melting, and melt-off (MF) is defined as the last melting day plus one. The melt duration (MD) at any pixel location is the total number of days when melting occurs.

A fixed-threshold melting record is created for comparison, hereafter referred to as FT3. In the FT3 record, melting is classified as where the enhanced-resolution $\sigma^{0}(\mathrm{t})$ is at or below $3 \mathrm{~dB}$ minus winter (June-July-August) mean backscatter, equivalent to the expected backscatter loss from a $2.8 \mathrm{~cm}$ layer of $1 \%$ volumetric water content as in Ashcraft and Long (2006). Melting events whose durations are shorter than three continuous days are removed from the melting record at each pixel following Tedesco et al. (2007).

For our study, we use a MATLAB ${ }^{\circledR}$ wavelet analysis software library (WaveLab 850) distributed by Stanford University and available at http://statweb.stanford.edu/ wavelab/. Because of the computationally intensive nature of the problem and of the high number of pixels necessary to cover the entire Antarctic continent at the spatial resolution considered here $(2.225 \mathrm{~km})$, we also made use of the MATLAB's parallel computing toolbox, running on a dedicated server using eight processing cores. In this configuration, one continent-scale melting season requires between 24 and $48 \mathrm{~h}$ of processing.

\section{Data sets}

\subsection{SeaWinds on QuikSCAT}

Enhanced spatial resolution melting maps (gridded at $2.225 \mathrm{~km})$ are derived from the enhanced-resolution SeaWinds (commonly referred to by the satellite name QuikSCAT) scatterometer data set distributed by MERS at Brigham Young University (http://www.mers.byu.edu/). The SeaWinds instrument is a conically scanning pencil-beamwidth scatterometer that records normalized radar crosssection measurements in the $\mathrm{Ku}$ band $(13.4 \mathrm{GHz})$. This instrument records both horizontal and vertical polarizations at a fixed incidence angle of $46^{\circ}$ for horizontal polarizations and $54.1^{\circ}$ for vertical polarizations (Long and Hicks, 2000). The effective $\sim 7 \mathrm{~km} \times 30 \mathrm{~km}$ instantaneous field of view of the QuikSCAT range-Doppler-processed "slice" product (Spencer et al., 2000) is enhanced through a scatterometer image reconstruction algorithm (SIR) developed at BYU. By combining multiple observations that are weighTed within with the senor's antenna function, the SIR algorithm can recover information attenuated at the antenna side lobe, thereby effectively increasing the spatial resolution of the standard scatterometer product (Early and Long, 2001). This resolution enhancement is done at the expense of increased signal noise. In view of the strong change in measured backscatter following snowmelt, the increase in signal noise does not affect melt detection considerably, hence allowing for the generation of a surface-melting product at a gridded spatial resolution of $2.225 \mathrm{~km}$ (Trusel et al., 2012; Barrand et al., 2013). In addition, the CWT method is well suited for noisy data sets since high-frequency, noisy transitions in backscatter are not likely to create a WTMML that extends to large scales (e.g., Liu et al., 2005) and those that do will decrease in $\left|W \sigma^{0}\right|$ with increasing scale, leading to negative Holder exponents and subsequently being removed in the melt detection methodology. 


\subsection{Automated weather stations}

Automated weather station data from the Antarctic Meteorological Research Center and Automatic Weather Station program, maintained by the Space Science and Engineering Center at the University of Wisconsin, Madison, are used to evaluate the results of the melt detection algorithms. For our comparison, we use the hand-corrected 3-hourly air temperature records. The AWS used in this study are Larsen Ice Shelf (lat. 67.01 S, long. $61.55 \mathrm{~W}$, elev. $17 \mathrm{~m}$ ), Uranus Glacier (lat. $71.43 \mathrm{~S}$, long. $68.93 \mathrm{~W}$, elev: $780 \mathrm{~m}$ ), Fossil Bluff (lat. $71.33 \mathrm{~S}$, long. $68.28 \mathrm{~W}$, elev. $63 \mathrm{~m}$ ), Butler Island (lat. $72.21 \mathrm{~S}$, long. $60.17 \mathrm{~W}$, elev. $91 \mathrm{~m}$ ), Pegasus South (lat. 77.99 S, long. 166.57 E, elev. $5 \mathrm{~m}$ ) and Limbert (lat. 75.91 S, long. $59.26 \mathrm{~W}$, elev. $40 \mathrm{~m}$ ). For each AWS, air-temperature measurements and backscatter are spatially and temporally coregistered using overpass times available from MERSSCP. Melting is determined from AWS air-temperature measurements where there are at least $2-3 \mathrm{~h}$ daily above-zero measurements. For Antarctica, extreme fluctuations in daily temperature often prevent the daily mean temperature from exceeding $0^{\circ} \mathrm{C}$, though satellites observations indicate that melting is likely taking place. A threshold below $0^{\circ} \mathrm{C}$ is often used to account for this fact (Tedesco and Monaghan, 2009; Van den Broeke et al., 2010), or in those cases where additional measurements are available, such as surface shortwave and long-wave radiative fluxes, melting may be determined using a simple thermodynamic model (Van den Broeke, 2005). From the lack of a defined sub-zero threshold for each AWS station, as well as of sufficient surface measurements for modeling approaches, we choose a temporal threshold of at least six hours of above-zero measurements in one day to establish melting conditions from AWS measurements and acknowledge that is a source of uncertainty in the AWS validation data set. This is equivalent to at least two daily above-zero measurements for the $3 \mathrm{~h}$ AWS air temperature data set. Once melt is estimated from AWS data, we study the number of days when the remote-sensingand air-temperature-based estimates agree (true positive); the omission error, computed as the percentage of days when air temperature indicates melting but the remote sensing-based approach does not (true negative); and the commission, computed as the percentage of days when the satellite data indicate melting but this is not occurring from the analysis of air temperature (false positive).

\section{Results}

\subsection{Comparison between QuikSCAT-derived melting and analysis of automated weather stations}

Results of the FT3 and dynamic wavelet-based (CWT) approaches are compared with estimates of melting derived from surface air temperatures measured by AWS. Because of the lack of in situ liquid water content or snow temperature measurements, melt is estimated from AWS air temperatures where the temperature is above zero for at least six hours per day. The time series of coregistered backscattering, air temperature and positive temperatures for the stations considered in this study are plotted in Fig. 2. We evaluate the agreement, commission and omission in percentage at each station, and the results are presented in Table 1. Agreement is defined as the percentage of cases where surface temperature and spaceborne-based estimates both detect melting. Commission is defined as the percentage of cases in which remote sensing algorithms indicate melting but AWS does not. Lastly, omission indicates the percentage of cases in which AWS suggests melting but the remote sensing algorithms do not.

For stations that experience at least 10 days of melt per year (Butler Island, Fossil Bluff and Larsen Ice Shelf stations), we find the highest rates of agreement. For these stations the FT3 approach performs with more agreement $(\sim 10 \%)$ than the CWT approach. The Larsen Ice Shelf and Fossil Bluff stations show the highest overall agreement, averaging $87 \%(77 \%)$ and $75 \%(66 \%)$ for the FT3 (CWT) approach for all years. Both of these stations have large magnitude and sustained change in backscatter over the melting season (Fig. 2a and b). For the Limbert, Butler Island and Uranus Glacier stations, shown in Fig. 2c, $d$ and e, respectively, the difference in agreement for the FT3 and CWT methods is greater, up to $43 \%$ (FT3 > CWT) between methods. At these stations, most of the melting occurs as shortduration events. This is not the case during the 2002-2003 and 2003-2004 seasons for the Limbert and Uranus Glacier stations, respectively, where the backscattering time series shows a substantial decrease in backscatter. In this case both remote sensing methods are in good agreement with AWS estimates. Figure $2 \mathrm{a}$ and $\mathrm{b}$ show that most of the difference between methods at these stations occurs during transitional periods, meaning near the seasonal MO or MF. For the Pegasus South station, the CWT method is in better agreement with AWS compared to FT3, with a $10 \%$ greater mean agreement. At the Pegasus South station the apparent backscatter response to melting, as shown in Fig. $2 \mathrm{f}$, is below detection by the FT3. Additionally, the Pegasus South station has the highest mean air temperature during melting conditions among these stations at $+2.16^{\circ} \mathrm{C}$ and a mean loss of $+1.86 \mathrm{~dB}$ (from winter mean) during AWS defined melting. Only the Uranus Glacier station has a smaller backscatter change, $+1.80 \mathrm{~dB}$, with an average temperature of $+0.79^{\circ} \mathrm{C}$ during melting. In contrast, the Larsen Ice Shelf averages a loss of $+15.07 \mathrm{~dB}$ with a mean temperature of $+1.06^{\circ} \mathrm{C}$ during AWS-defined melting.

Omission errors for all stations show an average of $12 \%$ fewer false positives for the FT3 compared to the CWT. For the Limbert AWS shown in Fig. 2e the CWT method has a maximum mean omission error of $83 \%$, compared to the FT3 at $40 \%$. The Limbert station has a short melting season, 
Table 1. Stations used in the AWS evaluation. Shown are the agreement (true positive), omission (false positive) and commission (true negative) relative differences from the comparison of melting estimated from AWS air temperatures and melt duration (MD) time series estimated using the FT3 and CWT melt algorithms.

\begin{tabular}{lrrrrrr}
\hline & \multicolumn{2}{c}{ Agreement } & \multicolumn{2}{c}{ Omission Error } & \multicolumn{2}{c}{ Commission Error } \\
AWS Station Name & \multicolumn{1}{c}{ FT3 } & \multicolumn{1}{c}{ CWT } & \multicolumn{1}{c}{ FT3 } & \multicolumn{1}{c}{ CWT } & \multicolumn{1}{c}{ FT3 } & CWT \\
\hline Butler Island & $50 \%(92 / 184)$ & $30 \%(55 / 184)$ & $50 \%(92 / 184)$ & $70 \%(129 / 184)$ & $2 \%(59 / 2708)$ & $21 \%(38 / 2708)$ \\
Fossil Bluff & $75 \%(123 / 164)$ & $66 \%(109 / 164)$ & $25 \%(41 / 164)$ & $34 \%(55 / 164)$ & $10 \%(91 / 923)$ & $10 \%(89 / 923)$ \\
Larsen Ice Shelf & $87 \%(413 / 477)$ & $77 \%(366 / 477)$ & $13 \%(64 / 477)$ & $23 \%(111 / 477)$ & $10 \%(285 / 2771)$ & $9 \%(238 / 2771)$ \\
Limbert & $60 \%(21 / 35)$ & $17 \%(6 / 35)$ & $40 \%(14 / 35)$ & $83 \%(29 / 35)$ & $0 \%(7 / 3225)$ & $0 \%(5 / 3225)$ \\
Pegasus South & $38 \%(46 / 121)$ & $48 \%(58 / 121)$ & $62 \%(75 / 121)$ & $52 \%(63 / 121)$ & $1 \%(14 / 2421)$ & $1 \%(28 / 2421)$ \\
Uranus Glacier & $36 \%(57 / 160)$ & $17 \%(27 / 160)$ & $64 \%(103 / 160)$ & $83 \%(133 / 160)$ & $1 \%(11 / 1641)$ & $0 \%(3 / 1641)$ \\
Total & $66 \%(752 / 1141)$ & $54 \%(621 / 1141)$ & $34 \%(389 / 1141)$ & $46 \%(520 / 1141)$ & $3 \%(467 / 13689)$ & $3 \%(401 / 13689)$ \\
\hline
\end{tabular}
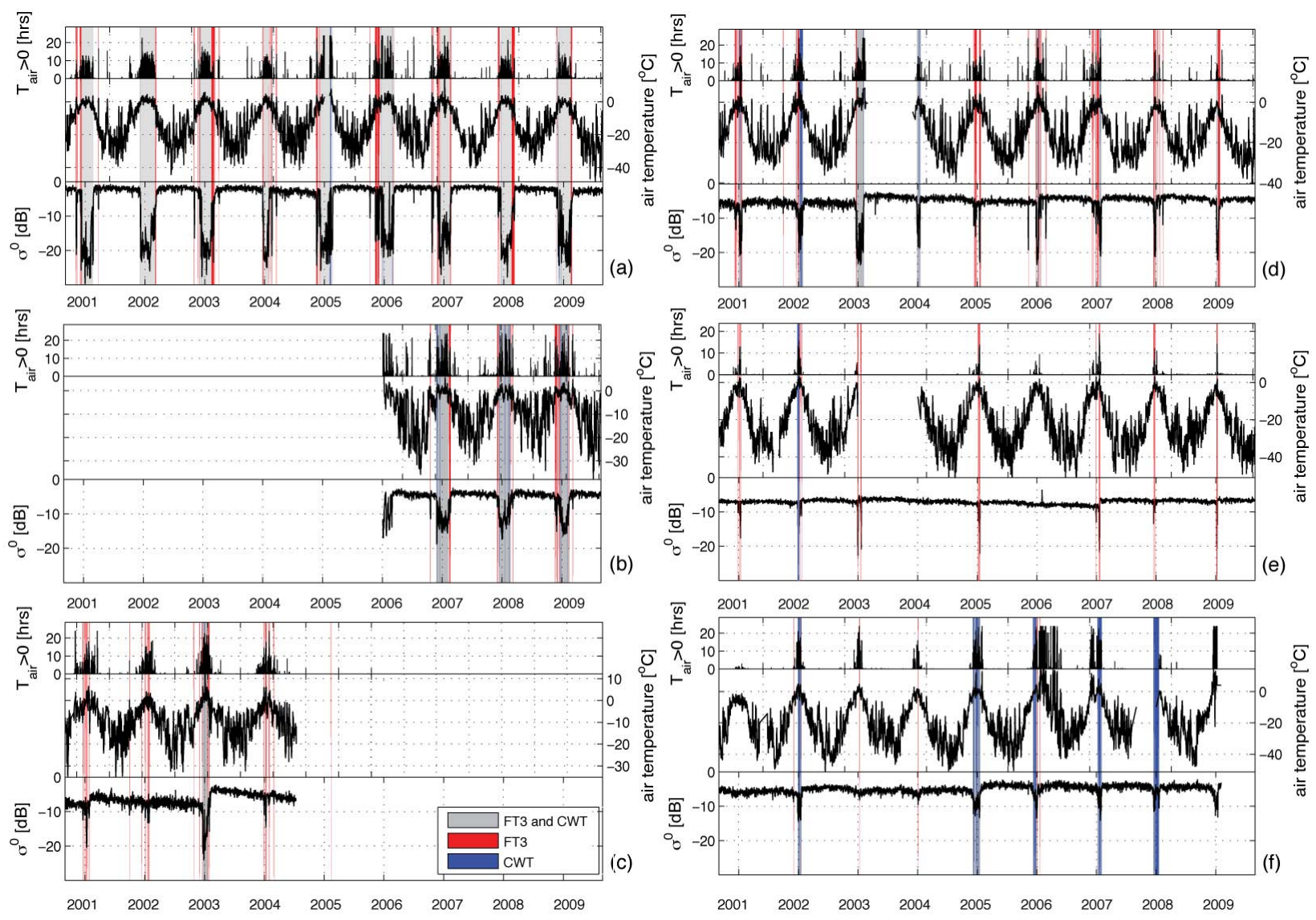

Fig. 2. AWS temperature records for (a) Larsen Ice Shelf, (b), Fossil Bluff, (c), Uranus Glacier, (d) Butler Island, (e) Limbert and (f) Pegasus South for 2000 to 2009 plotted with the corresponding QuikSCAT backscattering values. Times where the FT3 or CWT approaches estimate melting are shaded red and blue, respectively, while times where both methods agree are shaded grey.

averaging close to 4 days $\mathrm{yr}^{-1}$ in length from AWS-derived melting. The majority of these melting events are omitted using the CWT. Conversely, the FT3 approach detects these events with relatively high agreement $(83 \%)$. These findings are consistent with the basic principles of the CWT algorithm, which aims to detect only sustained melting events. For the Larsen Ice Shelf, we find the lowest rate of omission, averaging $34 \%$ (25\%) for the CWT (FT3). Commission er- rors are found to be small for both methods, averaging $3 \%$ for all stations for both the FT3 and CWT, respectively.

\subsection{Comparison between QuikSCAT melting algorithms}

The mean continent-scale seasonal (2000 through 2009) MD is shown in Fig. 3a and b for the FT3 and CWT approach, respectively. Figure $3 \mathrm{c}$ shows a map of the difference between 


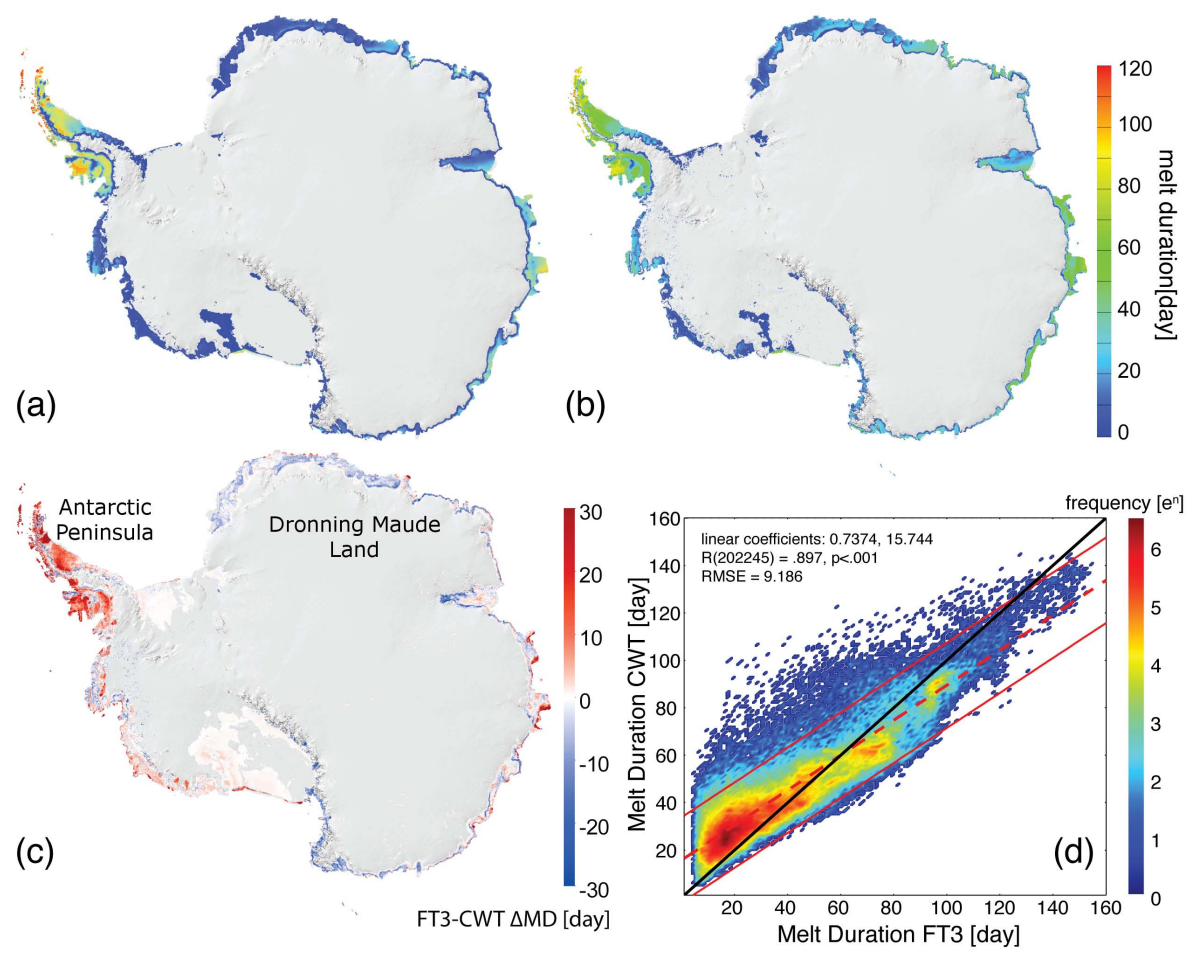

Fig. 3. (a) A map of mean (2000 through 2009) seasonal melt duration estimated from the SeaWinds sensor on QuikSCAT using a $3 \mathrm{~dB}$ below winter mean threshold (FT3) (b) and a continuous wavelet-based method (CWT). (c) The difference between mean MD from both methods is indicated as $\triangle \mathrm{MD}$ (FT3-CWT). The location of the Antarctic Peninsula (AP) and Dronning Maud Land (D) are labeled. (d) Autocorrelation analysis using a log-transformed two-axis histogram, where mean MD is compared for all areas where melt is detected by both methods.

MD approaches where $\Delta \mathrm{MD}=\mathrm{MD}_{\mathrm{FT} 3}-\mathrm{MD}_{\mathrm{CWT}}$. Although the spatial patterns of MD from the two methods are similar, systematic differences exists regionally and with elevation change. Results are presented and discussed in the context of Antarctica as a whole, specific regions and trends in $\triangle \mathrm{MD}$ with elevation.

\subsubsection{Continent-scale results}

For all areas and years, the CWT algorithm produces an average MD value of 41 days vs. 28 days obtained with the FT3 algorithm. The mean continent-scale melt index (MI), defined as the area subject to melting times the number of melting days, for the two methods is similar although larger for the CWT at $2.971 \times 10^{7}$ day $\mathrm{km}^{2}$ than the FT3 at $2.813 \times 10^{7}$ day $\mathrm{km}^{2}$. The MI detected by the CWT is larger than the FT3 because melting events detected by the CWT are continuous and do not contain short-duration intermittent non-melting classifications as in the FT3 melting records. This is also a factor in MD differences; however, the difference in MD can also be explained by the omission of smaller duration melting events by the CWT as shown in airtemperature comparisons at the Butler Island, Uranus Glacier and Limbert AWS. The inclusion of short-duration events in the FT3 record will greatly reduce the mean MD. The total melting extent, defined as the total surface area of Antarctica subject to at least one day of melting per season, is found to be $6.23 \%$ when using the CWT finds and $8.14 \%$ from the FT3.

The average MO, expressed as day of year, determined by the CWT approach is day 347 (e.g., 13 December for non-leap years) and in the case of the FT3 algorithm is day 352. The mean MF date for the whole of Antarctica between methods differs by 6 days, with the FT3 suggesting a later refreezing (day 28) than the CWT approach (day 22). The difference ( 5 days MO and 6 days MF) between the seasonal MO and MF obtained with the two approaches is small compared to the standard deviation $(\sigma)$ of either method, being $\sigma_{\mathrm{FT} 3}=26$ days and $\sigma_{\mathrm{CWT}}=16$ days for $\mathrm{MO}$ and $\sigma_{\mathrm{FT} 3}=28$ days and $\sigma_{\mathrm{CWT}}=17$ in MF over all locations and years.

The $10 \mathrm{yr}$ mean MD value per grid cell over Antarctica obtained with the FT3 method is plotted vs. the CWT method $10 \mathrm{yr}$ mean MD in Fig. 3d. Results of a linear least-squares regression and correlation analysis show that the results of the two algorithms are highly correlated $(r=.897, p<$ 0.001 ) with a root-mean-squared error (RMSE) of $\sim 9$ days. The CWT method finds a lesser MD than the FT3 approach over areas that experience a melting season shorter than the mean value of 34 days of both methods. The opposite is true 

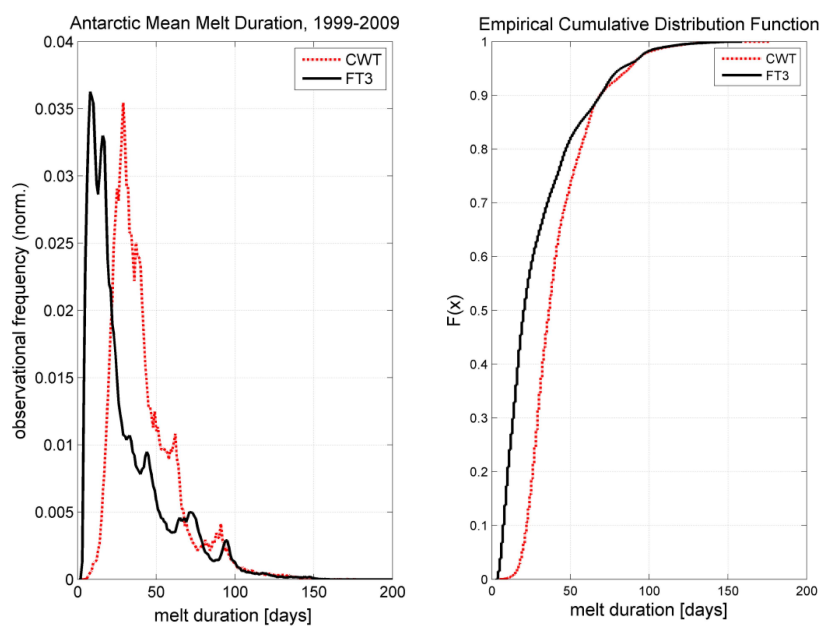

Fig. 4. (a) A histogram of all observed seasonal melt duration in days for the years 2000 through 2009 for the wavelet-based melt detection method (CWT) and a fixed-threshold method (FT3). It is found that the observations for the CWT are shifted towards longer durations due to the exclusion of short-duration melting events. (b) An empirical cumulative density function of observed melting duration.

for MD greater than 34 days, where the CWT method shows longer melt durations.

An analysis of the distribution of melt-duration occurrences, as shown in Fig. 4a, shows that the CWT algorithm finds more longer MDs relative to the FT3 and that the FT3 is much more likely to detect short-duration events. Close to $5 \%$ of MD values found by the FT3 are 10 days or less, while for the CWT method this accounts for less than $1 \%$ of all detected melting events (Fig. 4b). The inclusion of shortduration melting events using a fixed threshold leads to decreased mean MD value. The majority (> 50\%) of MDs for the FT3 method are under 27 days, compared to a 37-day MD for the CWT method. Both methods show better agreement for longer MD, where about $20 \%$ of all MDs for both methods are 60 days or longer.

\subsubsection{Regional results}

Detailed results are presented in this section for the Antarctic Peninsula and the coastal area of Dronning Maud Land (as shown in Fig. 3c). These regions are chosen because they exhibit the largest differences in regionally integrated $\Delta \mathrm{MD}$ or season length between algorithms.

Over the Antarctic Peninsula, seasonal mean MD values estimated by the CWT and FT3 are similar. The mean MD value obtained from the CWT approach is 55 days and 51 days from the FT3 approach. The spatial distribution of $\triangle \mathrm{MD}$ values obtained with the two approaches (Fig. 3c) indicates that the CWT shows generally larger MD values over the ice shelves of the Antarctic Peninsula than those obtained with the FT3 approach. The similarity in mean MD in the light of a visible difference in MD over large ice shelves can be attributed to the greater melting extent found by the FT3, compared to the CWT, over areas experiencing short melting durations. The melting index over the Antarctic Peninsula is $8.3 \%$ larger for the FT3 than the CWT (the relative difference is defined as $\left.\left|\mathrm{MI}_{1}-\mathrm{MI}_{2}\right| / \frac{1}{2}\left(\mathrm{MI}_{1}+\mathrm{MI}_{2}\right)\right)$.

When observing the seasonal melt initiation over the Antarctic Peninsula, we find that the mean MO date from the FT3 to be day 1 (e.g., 1 January) and the mean MO for the CWT is day 342. The MF dates for the CWT and FT3 over the peninsula are day 46 and day 33, respectively. The FT3 approach estimates a substantially longer (22 days) mean melting season for the Antarctic Peninsula compared to the CWT and most of this difference is due to the estimates of $\mathrm{MO}$.

An analysis of selected backscattering time series during the melting season along with regionally integrated melting is presented to show difference between the CWT and FT3 algorithms. For the Antarctic Peninsula during the 20042005 melting season, FT3 values (Fig. 5a, solid grey line) exhibit an early season (November, 2004) peak in ME reaching an extent of up to $\sim 80 \%$ of the yearly maximum for a period of $\sim 8$ days. This transient melting event is not observed in the time series of melting extent from the CWT approach as melt (Fig. 5a, dotted black line). A time series of backscatter from within the region and over this same period is shown in Fig. 5c. Melting is indicated by a shaded region for the CWT method, and by the location of the $3 \mathrm{~dB}$ threshold for the FT3 approach in Fig. 5c, we observe that the CWT excludes several melting events at the beginning of the season (outside of the shaded area) that correspond to the large increase in region-wide melting extent as shown by the FT3 (Fig. 5a). This omission by the CWT here is representative of the differences in melting extent observed regionally. Much of difference between methods over the Peninsula can be attributed to non-sustained short-term melting/refreezing events, as shown in Fig. 5a, before and after the period when most of the melting occurs. Additionally, it is clear that the MO date for most of the Antarctic Peninsula determined using the FT3 approach (defined as the first melting event greater than three days) will correspond to the brief November melting event that, as shown in Fig. 5a, may be several weeks prior to the main melting events. The omissions of melting events during transitional periods by the CWT method is also indicated in the AWS validation of the Butler Island, Limbert and Uranus Glacier AWS records.

The maximum in absolute $\triangle \mathrm{MD}$ between the FT3 and CWT method (Fig. 3c) is observed over areas of east Antarctica near the Donning Maud Land. Here $\triangle \mathrm{MD}$ averages -25 days. This difference can be attributed to both differences in the in mean season length (defined as the continuous period between MO and MF) and the time that melting is sustained through a season. Differences in mean seasonal length account for only $\sim 14 \%$ of the observed $\Delta \mathrm{MD}$ 

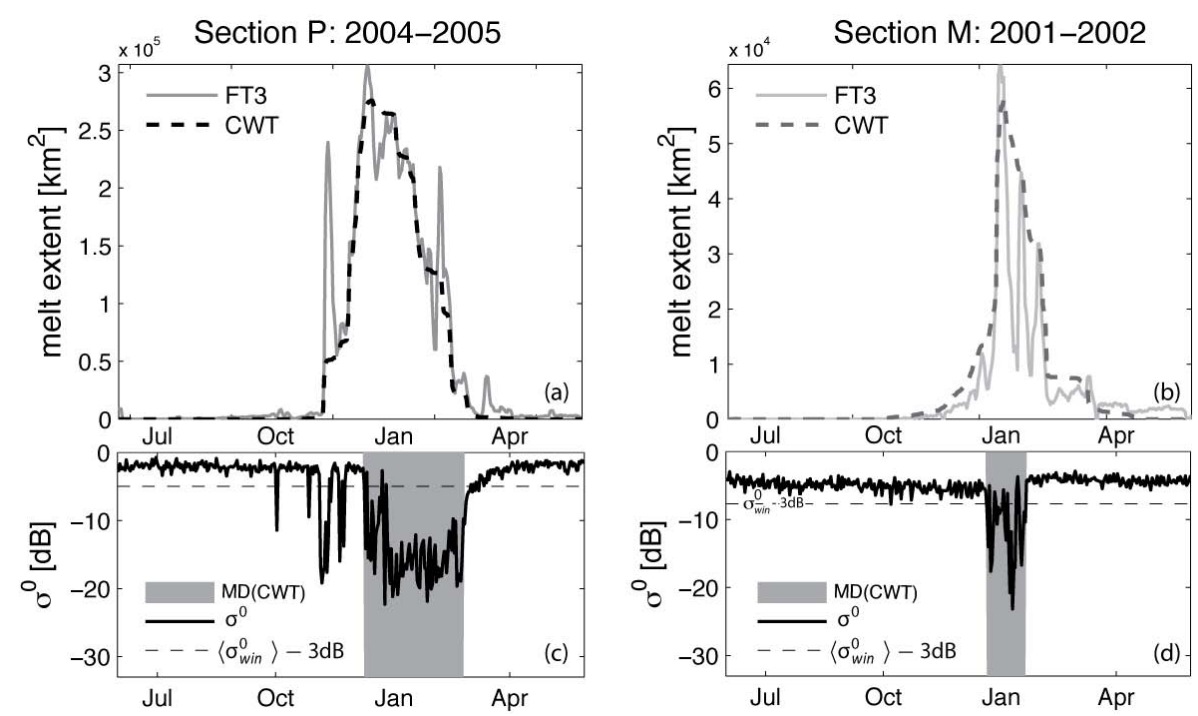

Fig. 5. (a) A time series of total integrated melt extent for 2004-2005 estimated using the FT3 and CWT methods over the Antarctic Peninsula (Section P) and (b) during the 2001-2002 melting season for Dronning Maud Land (Section M). Backscattering time series are plotted for (c) a representative pixel location for the Antarctic Peninsula during the 2004-2005 austral summer and (d) Dronning Maud Land during the 2001-2002 austral summer to illustrate the results of melt classification by of CWT (shaded) and FT3 methods (threshold indicated).

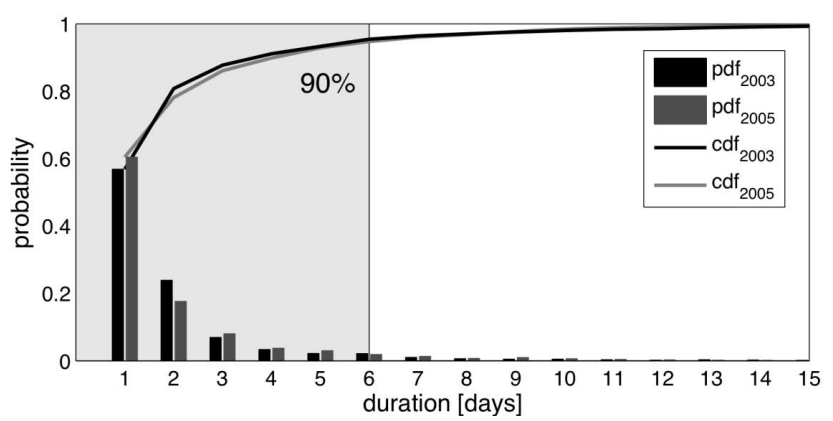

Fig. 6. The empirical probability density function (bar) and cumulative density function (line) of continuous melting periods per season observed over Antarctica (not the total per-pixel seasonal difference) for the 2003-2004 and 2005-2006 season that are found using a FT3 but rejected in by CWT.

found between methods. The percentage of melt days per melting season length (calculated as (MF-MO)/MD) is $65 \%$ for the FT3 method and close to $95 \%$ for the CWT approach. This important difference can be partly attributed to threshold values that underestimate the actual backscattering response to increasing liquid water content and as a result backscatter with melting is close in magnitude to the to seasonal in backscatter threshold (e.g., $3 \mathrm{~dB}$ ). With signal noise, a fixed-threshold algorithm will alternate between classifications of melting and refreeze as backscatter fluctuates around the backscatter threshold. Alternatively, similar fluctuations in backscatter could be attributed to rapid melt-refreeze events in areas where the liquid water content is not sustained through diurnal refreeze cycles. These cases are difficult to validate without further information and are a weakness of fixed-threshold algorithms in varying snow property and temperature regimes. In the CWT methodology, sustained deviations from wintertime conditions will be detected and classified as melt until an additional refreeze transition occurs, regardless of intermittent non-sustained (negative $a$ ) fluctuations in backscatter.

A time series of ME and $\sigma^{0}$ for Dronning Maud Land are shown in Fig. 5b and d. Here, the CWT method finds a greater regionally integrated MI with respect to the FT3 method. A time series of $\sigma^{0}$ chosen from within Dronning Maud Land, as in Fig. 5c. This backscatter series indicates that the FT3 method will classify multiple melt-refreeze events as $\sigma^{0}$ changes rapidly around the threshold value, while the CWT will record a single melting event. This will lead to estimates of a shorter MD by the FT3. It is found that this case is representative of the majority of regions with $-\Delta \mathrm{MD}$. Melting events as shown in Fig. $5 \mathrm{~d}$ will not result in considerable differences in MO or MF dates.

An estimate of the average length of MD omitted by the CWT (i.e., the minimum number of days where the CWT will detect melting) is determined empirically from melting records over the Antarctic Peninsula. Figure 6 shows the cumulative sum (lines) and histogram (bars) of the length of melting days obtained from the two approaches over the Antarctic Peninsula for two selected years of 2003-2004 and 2005-2006; these seasons are selected as an example of a relatively low and high mean melting index, respectively. It is important to note that this is not an analysis of total MD per season, as shown in Fig. 4, but rather the length of a period during the melting season where FT3 detects any melting 


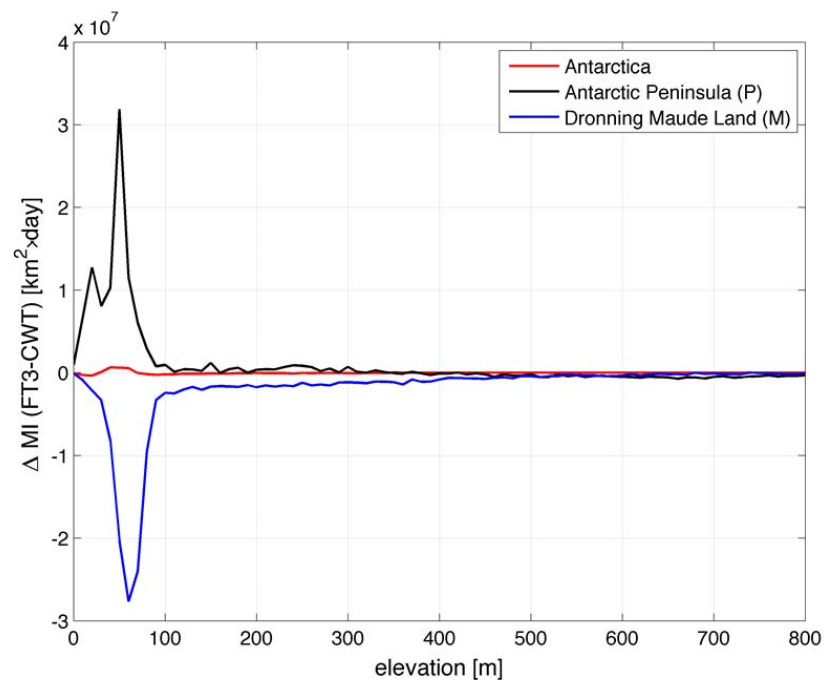

Fig. 7. An analysis of the difference in melting index $\left(\Delta \mathrm{MI}=\mathrm{MI}_{\mathrm{FT} 3}-\mathrm{MI}_{\mathrm{CWT}}\right)$ estimates from the FT3 and CWT methods at a range of elevations for the entire Antarctic continent (red line) as well as the Antarctic Peninsula (black line) and Dronning Maud Land (blue line).

event and CWT does not. During the 2003-2004 season, $\sim 60 \%$ of MD values differ by only one day, $\sim 20 \%$ show differences of two days, with the remaining values differing by more than six days ( $\sim 90 \%$ of observations are six days or less). This six-day duration is similar to the temporal filtering methods used in previous melting studies to eliminate transient melting events (e.g., three days; Tedesco et al., 2007).

\subsubsection{Elevation}

Figure 7 shows results concerning the difference between the outputs of the two approaches as a function of elevation for the Antarctic Peninsula, Dronning Maud Land and the whole of Antarctica. For the Dronning Maud Land region, the melt index difference between the two methods $\left(\Delta \mathrm{MI}=\mathrm{MI}_{\mathrm{FT} 3}-\mathrm{MI}_{\mathrm{CWT}}\right)$ is negative, independent of elevation. For the Antarctic Peninsula, however, the mean difference between methods is positive, and will vary with elevation. For areas below $400 \mathrm{~m}$ a.s.l. the CWT method underestimates MI with respect to the FT3 method. Conversely, above $400 \mathrm{~m}$ a.s.l., the MI difference becomes negative. Building on our previous analysis in this paper, we infer that for the Antarctic Peninsula at lower elevations we find that the melt difference is due to the omission of short-duration melting events, while at higher elevations we find a that melt detection differences are more closely related to either short melt-refreeze cycles at high elevations or a lesser backscatter response to snow wetness. This may indicate the need for terrain correction when using fixed-threshold methods.
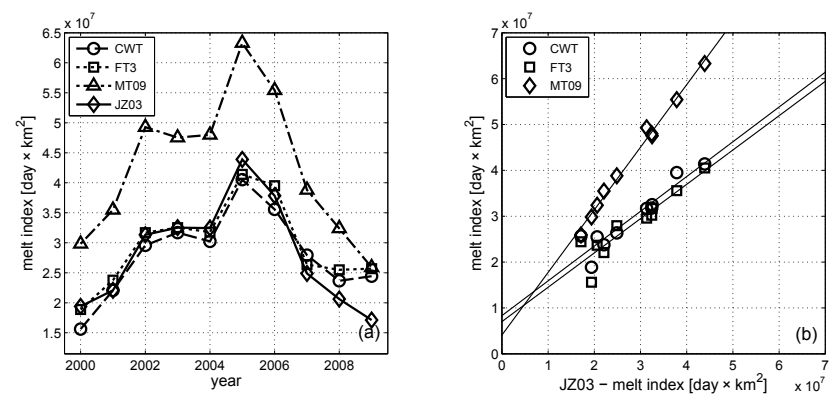

Fig. 8. (a) The time series of total melt index (MI), in day $\mathrm{km}^{2}$, for the Antarctic continent plotted for the years 1999 through 2009 derived from the FT3 and CWT methods on an enhanced-resolution QuikSCAT active microwave data set along with estimates from the MT09 and M+K30 methods and an SSM/I data set. (b) The correlation between the FT3, QuikSCAT data set MI estimates and the CWT, M+K30 and MT09 methods is indicated using a linear regression.

\subsection{Comparison with results from passive microwave measurements}

We compare melting records from passive microwave SSM/I observations using approaches proposed in the literature with the outputs of both the CWT and FT3 methods. The SSM/I-derived melting is produced using two methods. The first is a fixed-threshold approach as in Zwally and Fiegles (1994), here denoted M+30K. The second data set is produced using a dynamic electromagnetic modelingbased detection approach as in Tedesco (2009), here denoted MT09. Outputs from both methods are projected onto the $2.225 \mathrm{~km}$ QuikSCAT grid using nearest-neighbor interpolation. Enhanced-resolution passive microwave brightness temperatures generated using the SIR algorithm are available for Antarctica (Long and Stroeve, 2011). Melting records based on these data would reduce scaling discrepancies between the active and passive microwave melt records reported here and provide a more consistent analysis. This will be explored in further studies.

The values of seasonally integrated MI for Antarctica for both active and passive microwave methods are plotted in Fig. 8a. The M+30K and CWT approaches show the most similar magnitude in seasonal MI, where the relative difference is $9 \%$. This is only $2 \%$ greater than the difference between the CWT and FT3 methods (7\%). There is a slightly greater relative difference between the FT3 and M+30K of $11 \%$. The MT09 method finds on average a $40 \%$ greater MI than the FT3 method, and $35 \%$ greater than the CWT.

For individual seasons, all methods find a MI maximum during the 2004-2005 period. The active and passive methods, however, do not agree on the year of minimum MI. Indeed, both the CWT and FT3 approaches find a minimum MI during the 1999-2000 seasons, while the passive methods find a minimum during the 2008-2009 melting 
season, where most of this difference is from the Antarctic Peninsula. Seasonally integrated melting indices derived using the passive microwave methods are well correlated with the QuikSCAT-derived melting records. This relationship is shown in Fig. 8b. The best agreement between active and passive microwave records is found between the CWT and $\mathrm{M}+30 \mathrm{~K}$, as indicated in Table 2a. Further, both MT09 and $\mathrm{M}+30 \mathrm{~K}$ have a greater degree of correlation and a lower RMSE for the CWT than compared to the FT3.

The spatial differences between the mean MD estimated using the $\mathrm{M}+30 \mathrm{~K}$ approach and the CWT and FT3 is shown in Fig. 9a and b, respectively. These maps indicate spatial patterns in the magnitude of difference between methods $\left(\Delta \mathrm{MD}_{\mathrm{FT} 3}=\mathrm{M}+30 \mathrm{~K}-\mathrm{FT} 3\right)$. Over large ice shelves (e.g., the Larsen and Amery ice shelves), $\Delta \mathrm{MD}_{\mathrm{FT} 3}$ is close to +10 days (Fig. 9a). Over the same regions, the $\Delta \mathrm{MD}$ between the $\mathrm{M}+30 \mathrm{~K}$ and the CWT algorithms is close to +20 days (Fig. 9b). The tendency for the passive microwave data to overestimate active microwave estimates (close to +10 or $+20 \Delta \mathrm{MD}$ in most cases) is usually bordered, to some degree, by an area of underestimation by the passive measurements. The majority of areas that exhibit melting in Antarctica are generally at ice-ocean boundaries. For the Antarctic Peninsula (among other places) areas of melt occur adjacent to sharp contrasts in elevation. For many of these areas sub-pixel mixing will likely lead to a decrease in the observed brightness temperatures of some melting areas. For example, over the coastal regions of Dronning Maud Land we find that the systematic occurrence of positive $\triangle \mathrm{MD}$ bordered negative $\Delta \mathrm{MD}$. These negative $\Delta \mathrm{MDs}$ are found adjacent to ocean pixels and high elevations and are likely due to a sub-pixel mixing effect. In another case, the relatively narrow King George VI (lat. -71.965, long. -67.807) Ice Shelf, located roughly east of Wilkens Ice Shelf (lat. -67.525, long. -62.775), appears to increase the apparent MD of the surrounding high-elevation areas for the passive microwave case, resulting in a large positive $\Delta \mathrm{MD}$. Since mixed pixel effects dominate the spatial differences between methods, it is difficult to determine a relationship between MD methods over similar areas other than the positive $\sim 10$ days (FT3) and $\sim 20$ days (CWT) reported previously.

An analysis of correlation between colocated melting durations from active microwave data sets and the $\mathrm{M}+30 \mathrm{~K}$ method indicates that the FT3 has a higher degree of correlation with the passive microwave $\mathrm{M}+30 \mathrm{~K}$ method Table $2 \mathrm{~b}$. It is also found that AMW methods find an RMSE of $\sim 18$ days in comparison with both the M+30 and MT09. The relationship between spatially colocated data records are illustrated the Fig. 9c and d. A first-order least-squares regression between $\mathrm{CWT}$ and $\mathrm{M}+30 \mathrm{~K}$ shows an $\sim 13$-day positive bias. There is an $\sim 3$-day positive bias between the FT3 and $\mathrm{M}+30 \mathrm{~K}$ from similar analysis. Artifacts that appear as vertical striping of data points indicate a high degree of variability for many pixels with similar MD as detected using the $\mathrm{M}+30 \mathrm{~K}$. These are likely a result of a high degree of sub-pixel variability due to the difference in spatial resolution as previously discussed. In Fig. 9c and d, we see that a larger component of the melt data set for the FT3 method falls along the $1: 1$ line. The CWT method appears to underestimate $\mathrm{MD}$ as compared to $\mathrm{M}+30 \mathrm{~K}$, or vice versa. It also appears that the CWT method finds greater MD for shorter durations, evident by a cluster of points 0 to $50 \mathrm{MD}$ for CWT and 0 to 20 days for $\mathrm{M}+30 \mathrm{~K}$. This relationship is similar to observation between active microwave methods. The relatively strong agreement between active and passive melting indices, shown in Fig. 8a, indicates that the high sub-pixel variability is averaged out when integrated over the entire data set.

\section{Summary and conclusion}

The use of a combined continuous wavelet transform and multiscale analysis is able to detect changes in the backscattering signal upon an increase in liquid water content. This methodology does not require an estimation of the expected response to snowmelt and is therefore applicable to spatially variable snow characteristics and across instrumentation. It has also been found to be effective in the light of increased signal noise. Multiscale analysis provides a quantifiable measure of the nature of transitions in backscatter in terms of relative persistence and rate of transition. This can be used in classification. Here we use multiscale analysis to separate sporadic from persistent melting events.

Estimated mean MD derived from the novel wavelet approach and a more standard fixed-threshold method are very well correlated, $r=.897(p<0.001)$ with an RMSE of $\sim 9$ days. In mean MD, we found that there is as a $19 \%$ relative difference between methods, and the CWT method averages 13 days longer MD than the FT3. This difference in MD is largely due to the omission of shorter duration melting events, most of which are six days or less.

Measures of MI from both measures have a $5.5 \%$ relative difference, the CWT greater than the FT3. Areas where the CWT is greater in mean MD are found to have intermittent refreezing events or a backscatter response to liquid water content that is close to or below the $3 \mathrm{~dB}$ threshold value with signal noise. This is found over much of Dronning Maud Land and at high elevations over the Antarctic Peninsula.

At a continental scale the mean melting season length (MF-MO) estimated in both methodologies agrees to within two days. On the Antarctic Peninsula, shorter duration melting events during the transitional periods are omitted by the CWT leading to a melt onset 12 days earlier detected by the FT3 method. This is illustrated during the 2004-2005 season, where the melt extent reaches $\sim 80 \%$ of its maximum seasonal value for close to 8 days and the CWT method does not detect melting over an equivalent extent until several weeks later. The MO found by the CWT is closer in time to the start of a sustained melting period. The FT3 defines 
Table 2. The correlation $(r)$ and the root-mean-squared error (RMSE) between surface melting data sets for (a) seasonally integrated melting index (b) and spatially coincident mean melting duration.

\begin{tabular}{llrrr}
\hline (a) & CWT & FT3 & M+30K & MT09 \\
\hline CWT & $r$ & $0.972(p<0.001)$ & $0.934(p<0.001)$ & $0.931(p<0.001)$ \\
& RMSE $\left[\right.$ day $\left.\times \mathrm{km}^{2}\right]$ & $1.89 \times 10^{6}$ & $2.74 \times 10^{6}$ & $1.56 \times 10^{7}$ \\
FT3 & $r$ & - & $0.922(p=0.01)$ & $0.911(p=0.002)$ \\
& RMSE $\left[\right.$ day $\left.\times \mathrm{km}^{2}\right]$ & - & $3.10 \times 10^{6}$ & $1.41 \times 10^{7}$ \\
\hline (b) & CWT & FT3 & $\mathrm{M}+30 \mathrm{~K}$ & MT09 \\
\hline CWT & $r$ & $0.897(p<0.001)$ & $0.664(p<0.001)$ & $0.663(p<0.001)$ \\
& RMSE [day] & 9 & 19 & 18 \\
FT3 & $r$ & - & $0.782(p<0.001)$ & $0.672(p<0.001)$ \\
& RMSE [day] & - & 17 & 17 \\
\hline
\end{tabular}
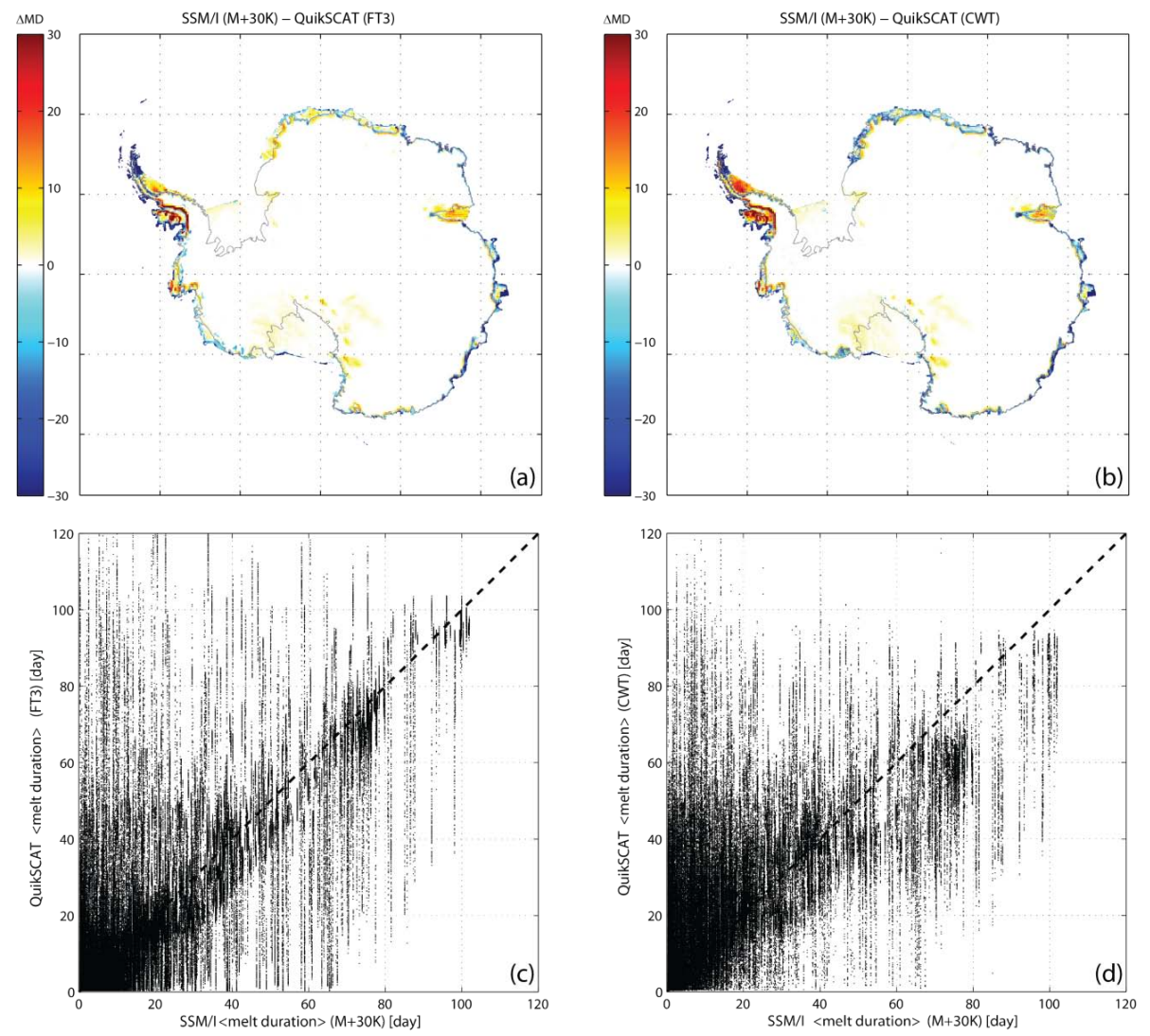

Fig. 9. The difference in average melt duration $\left(\triangle \mathrm{MD}=\mathrm{MD}_{\mathrm{SSM} / \mathrm{I}}-\mathrm{MD}_{\text {QuikSCAT }}\right)$ over the period of 1999-2009 between the up-sampled passive microwave SSM/I data set, where melt is estimated using the M+K30 approach, and the enhanced-resolution QuikSCAT scatterometer data set, where melt is estimated using the (a) FT3 and (b) CWT methods. Per-pixel scatterplots of average melt duration between SSM/I $(\mathrm{M}+30 \mathrm{~K})$ and the (c) FT3 and (d) CWT approaches.

MO coincident to the start of a transitional period of multiple freeze-thaw cycles.

From comparison with AWS we find that the FT3 has higher overall level of agreement with air-temperature measurements, with a $66 \%$ total agreement compared to the $54 \%$ from the CWT method. This is true for all AWS apart from the Pegasus South station, where the CWT has a $10 \%$ greater agreement than the FT3 method. The FT3 method has a better agreement in general because of its ability to measure short-duration melting events, which are common for several stations (e.g., Limbert). For the Pegasus South AWS, it appears that as the melting season occurs with a relatively low loss in backscatter with melting conditions, it is therefore never consistently under the $3 \mathrm{~dB}$ threshold. 
Many of these above-zero temperature events are not long lasting in nature, and to evaluate the CWT method solely using agreement assessments does not indicate the true utility of this approach to create a record of sustained melting events.

Compared to $\mathrm{M}+30 \mathrm{~K}$, a passive microwave-derived approach, both active microwave melting records find a similar yearly MI, where the FT3 is within $11 \%$ and the CWT within $9 \%$ relative difference. These methods find a greater level of disagreement with a dynamic thresholding approach, MT09. The CWT methods find a greater overall agreement in temporal trend for both PMW methods, for the $\mathrm{M}+30 \mathrm{~K}$ method $r=.943(p<0.001)$ with CWT and $r=.922(p=0.001)$ for the FT3 method. Spatially, we find that comparison is dominated by a mixed pixel effect, making it difficult to determine the difference between melt duration on a per-pixel basis. The FT3 method has a higher degree of spatial correlation with passive microwave $(\mathrm{M}+30 \mathrm{~K})$ approaches than the CWT, with significant variability in AMW-derived MD for similar passive microwave measurements. Since PMW pixels are $\sim 10$ times the scale of the spatially enhanced QuikSCAT product, we attribute this variability to mixed pixel effects. Based on the strong correlation in yearly MI totals, the differences in spatial variability appear to be averaged out over the total area.

In conclusion, the CWT methodology is an alternative to a fixed-threshold method that works well on data with increased signal noise, an application where threshold-based methods find difficulty. This approach is also able to classify melting events based on relative duration. This allows for the focused measurements of persistent melting, rather than total integrated melting, a utility that may be useful studying long-term trends in melting

Acknowledgements. The authors acknowledge the support of NSF grant ANT-1141993. The authors acknowledge D. Long and the NASA Jet Propulsion Laboratory PO.DAAC for providing the enhanced-resolution scatterometer products. The authors appreciate the support of the Automatic Weather Station program and the Antarctic Meteorological Research Center for the data set, data display, information and further assistance (M. Lazzara, NSF grant numbers ARC-0713843, ANT-0944018, and ANT-1141908). This research was supported in part by National Science Foundation grants CNS-0958379 and CNS-0855217 and the City University of New York High Performance Computing Center at the College of Staten Island.

Edited by: J. Stroeve

\section{References}

Abdalati, W. and Steffen, K.: Greenland ice sheet melt extent: 1979-1999, J. Geophys. Res.-Atmos., 106, 33983-33988, doi:10.1029/2001jd900181, 2001.
Alexandrescu, M., Gibert, D., Hulot, G., Lemouel, J. L., and Saracco, G.: Detection of Geomagnetic Jerks Using Wavelet Analysis, J. Geophys. Res.-Sol. Ea., 100, 12557-12572, doi:10.1029/95JB00314, 1995.

Ashcraft, I. S. and Long, D. G.: Comparison of methods for melt detection over Greenland using active and passive microwave measurements, Int. J. Remote Sens., 27, 2469-2488, doi:10.1080/01431160500534465, 2006.

Barrand, N. E., Vaughan, D. G., Steiner, N., Tedesco, M., Munneke, P. K., Van den Broeke, M. R., and Hosking, J. S.: Trends in Antarctic Peninsula surface melting conditions from observations and regional climate modeling, J. Geophys. Res.-Earth, 118, 315-330, 2013.

Bromwich, D. H. and Nicolas, J. P.: Sea-Level Rise Ice-sheet uncertainty, Nat. Geosci., 3, 596-597, doi:10.1038/ngeo946, 2010.

Chen, J. L., Wilson, C. R., and Tapley, B. D.: Interannual variability of Greenland ice losses from satellite gravimetry, J. Geophys. Res.-Sol. Ea., 116, B07406, doi:10.1029/2010jb007789, 2011.

Comiso, J.: Polar oceans from space, Springer, New York, 2010.

Daubechies, I.: Ten lectures on wavelets, Society for Industrial and Applied Mathematics, Philadelphia, Pa., 1992.

Dowdeswell, J. A.: Atmospheric science - The Greenland Ice Sheet and global sea-level rise, Science, 311, 963-964, doi:10.1126/science.1124190, 2006.

Early, D. S. and Long, D. G.: Image reconstruction and enhanced resolution imaging from irregular samples, IEEE T. Geosci. Remote, 39, 291-302, doi:10.1109/36.905237, 2001.

Hansen, J., Ruedy, R., Sato, M., and Lo, K.: Global Surface Temperature Change, Rev. Geophys., 48, Rg4004, doi:10.1029/2010rg000345, 2010.

Herrmann, F. J.: Singularity characterization by monoscale analysis: Application to seismic imaging, Appl. Comput. Harmon. A., 11, 64-88, doi:10.1006/acha.2000.0349, 2001.

Holland, P. R., Corr, H. F. J., Pritchard, H. D., Vaughan, D. G., Arthern, R. J., Jenkins, A., and Tedesco, M.: The air content of Larsen Ice Shelf, Geophys. Res. Lett., 38, L10503, doi:10.1029/2011GL047245, 2011.

Holschneider, M.: Wavelets: an analysis tool, Clarendon Press, Oxford University Press, Oxford, New York, 1995.

Hughes, T. J.: The Weak Underbelly of the West Antarctic Ice-sheet, J. Glaciol., 27, 518-525, 1981.

Joshi, M., Merry, C. J., Jezek, K. C., and Bolzan, J. F.: An edge detection technique to estimate melt duration, season and melt extent on the Greenland ice sheet using passive microwave data, Geophys. Res. Lett., 28, 3497-3500, doi:10.1029/2000GL012503, 2001.

Joughin, I. and Alley, R. B.: Stability of the West Antarctic ice sheet in a warming world, Nat. Geosci., 4, 506-513, doi:10.1038/ngeo1194, 2011.

Le Gonidec, Y., Gibert, D., and Proust, J. N.: Multiscale analysis of waves reflected by complex interfaces: Basic principles and experiments, J. Geophys. Res.-Sol. Ea., 107, 2184, doi:10.1029/2001JB000558, 2002.

Lemke, P., Ren, J., Alley, R. B., Allison, I., Carrasco, J., Flato, G., Fujii, Y., Kaser, G., Mote, P., Thomas R. H., and Zhang, T.: Observations: Changes in Snow, Ice and Frozen Ground, in: Climate Change 2007: The Physical Science Basis. Contribution of Working Group I to the Fourth Assessment Report of the Intergovernmental Panel on Climate Change, edited by: Solomon, S., 
Qin, D., Manning, M., Chen, Z., Marquis, M., Averyt, K. B., Tignor, M., and Miller, H. L., Cambridge University Press, Cambridge, UK and New York, NY, USA, 2007.

Liu, H., Wang, L., and Jezek, K. C.: Wavelet-transform based edge detection approach to derivation of snowmelt onset, end and duration from satellite passive microwave measurements, Int. J. Remote Sens., 26, 4639-4660, 2005.

Long, D. G. and Hicks, B. R.: Standard BYU QuikScat/SeaWinds land/ice image products, Brigham Young Univ., Provo, UT, QuikScat Image Product documentation, 2000.

Long, D. G. and Stroeve, J.: Enhanced-Resolution SSM/I and AMSR-E Daily Polar Brightness Temperatures, Boulder, Colorado, USA: NASA DAAC at the National Snow and Ice Data Center, 2011.

MacAyeal, D. R., Scambos, T. A., Hulbe, C. L., and Fahnestock, M. A.: Catastrophic ice-shelf break-up by an iceshelf-fragment-capsize mechanism, J. Glaciol., 49, 22-36, doi:10.3189/172756503781830863, 2003.

Mallat, S. G.: A wavelet tour of signal processing, 2nd Edn., Academic Press, San Diego, 1999.

Mallat, S. G. and Hwang, W. L.: Singularity Detection and Processing with Wavelets, Ieee T. Inf. Th., 38, 617-643, doi:10.1109/18.119727, 1992.

Mallat, S. G. and Zhong, S.: Characterization of Signals from Multiscale Edges, Ieee T. Pattern Anal., 14, 710-732, doi:10.1109/34.142909, 1992.

Mote, T. L. and Anderson, M. R.: Variations in Snowpack Melt on the Greenland Ice-sheet Based on Passive-microwave Measurements, J. Glaciol., 41, 51-60, 1995.

Mote, T. L., Anderson, M. R., Kuivinen, K. C., and Rowe, C. M.: Passive microwave-derived spatial and temporal variations of summer melt on the Greenland ice sheet, Ann. Glaciol., 17, p. 233, 1993.

Nghiem, S. V., Steffen, K., Kwok, R., and Tsai, W. Y.: Detection of snowmelt regions on the Greenland ice sheet using diurnal backscatter change, J. Glaciol., 47, 539-547, doi:10.3189/172756501781831738, 2001.

Nghiem, S. V, Steffen, K., Neumann, G., and Huff, R.: Snow accumulation and snowmelt monitoring in Greenland and Antarctica, in: Dynamic Planet, 31-38, Springer, 2007.

Ohmura, A.: Physical basis for the temperature-based melt-index method, J. Appl. Meteorol., 40, 753-761, doi:10.1175/15200450(2001)040<0753:pbfttb>2.0.co;2, 2001.

Overpeck, J. T., Otto-Bliesner, B. L., Miller, G. H., Muhs, D. R., Alley, R. B., and Kiehl, J. T.: Paleoclimatic evidence for future ice-sheet instability and rapid sea-level rise, Science, 311, 17471750, doi:10.1126/science.1115159, 2006.

Rignot, E. and Thomas, R. H.: Mass balance of polar ice sheets, Science, 297, 1502-1506, 2002.

Rignot, E., Casassa, G., Gogineni, P., Krabill, W., Rivera, A., and Thomas, R.: Accelerated ice discharge from the Antarctic Peninsula following the collapse of Larsen B ice shelf, Geophys. Res. Lett., 31, L18401, doi:10.1029/2004GL020697, 2004.

Rignot, E., Velicogna, I., Van den Broeke, M. R., Monaghan, A., and Lenaerts, J.: Acceleration of the contribution of the Greenland and Antarctic ice sheets to sea level rise, Geophys. Res. Lett., 38, L05503, doi:10.1029/2011gl046583, 2011.

Rott, H., Muller, F., Nagler, T., and Floricioiu, D.: The imbalance of glaciers after disintegration of Larsen-B ice shelf, Antarctic
Peninsula, Cryosphere, 5, 125-134, doi:10.5194/tc-5-125-2011, 2011.

Scambos, T. A., Bohlander, J. A., Shuman, C. A., and Skvarca, P.: Glacier acceleration and thinning after ice shelf collapse in the Larsen B embayment, Antarctica, Geophys. Res. Lett., 31, L18402, doi:10.1029/2004g1020670, 2004.

Scambos, T. A., Fricker, H. A., Liu, C. C., Bohlander, J., Fastook, J., Sargent, A., Massom, R., and Wu, A. M.: Ice shelf disintegration by plate bending and hydro-fracture: Satellite observations and model results of the 2008 Wilkins ice shelf break-ups, Earth Planet. Sc. Lett., 280, 51-60, doi:10.1016/j.epsl.2008.12.027, 2009.

Shepherd, A. and Wingham, D.: Recent sea-level contributions of the Antarctic and Greenland ice sheets, Science, 315, 15291532, doi:10.1126/science.1136776, 2007.

Shepherd, A., Ivins, E. R., Geruo, A., Barletta, V. R., Bentley, M. J., Bettadpur, S., Briggs, K. H., Bromwich, D. H., Forsberg, R., and Galin, N.: A reconciled estimate of ice-sheet mass balance, Science, 338, 1183-1189, 2012.

Spencer, M. W., Wu, C. L., and Long, D. G.: Improved resolution backscatter measurements with the SeaWinds pencilbeam scatterometer, Ieee T. Geosci. Remote, 38, 89-104, doi:10.1109/36.823904, 2000.

Steffen, K., Nghiem, S. V, Huff, R., and Neumann, G.: The melt anomaly of 2002 on the Greenland Ice Sheet from active and passive microwave satellite observations, Geophys. Res. Lett., 31, L20402, doi:10.1029/2004GL020444, 2004.

Stiles, W. H. and Ulaby, F. T.: The Active and Passive Microwave Response to Snow Parameters .1. Wetness, J. Geophys. Res.-Oc. Atmos., 85, 1037-1044, doi:10.1029/JC085iC02p01037, 1980.

Tedesco, M.: Assessment and development of snowmelt retrieval algorithms over Antarctica from K-band spaceborne brightness temperature (1979-2008), Remote Sens. Environ., 113, 979997, doi:10.1016/j.rse.2009.01.009, 2009.

Tedesco, M. and Monaghan, A. J.: An updated Antarctic melt record through 2009 and its linkages to high-latitude and tropical climate variability, Geophys. Res. Lett., 36, L18502, doi:10.1029/2009GL039186, 2009.

Tedesco, M., Abdalati, W., and Zwally, H. J.: Persistent surface snowmelt over Antarctica (1987-2006) from $19.35 \mathrm{GHz}$ brightness temperatures, Geophys. Res. Lett., 34, L18504, doi:10.1029/2007g1031199, 2007.

Torinesi, O., Fily, M., and Genthon, C.: Variability and trends of the summer melt period of Antarctic ice margins since 1980 from microwave sensors, J. Climate, 16, 1047-1060, doi:10.1175/1520-0442(2003)016<1047:VATOTS>2.0.CO;2, 2003.

Trusel, L. D., Frey, K. E., and Das, S. B.: Antarctic surface melting dynamics: Enhanced perspectives from radar scatterometer data, J. Geophys. Res.-Earth, 117, 2156-2202, doi:10.1029/2011JF002126, 2012.

Ulaby, F. T. and Stiles, W. H.: The Active and Passive Microwave Response to Snow Parameters 2: Water Equivalent of Dry Snow, J. Geophys. Res.-Oc. Atm., 85, 1045-1049, doi:10.1029/JC085iC02p01045, 1980.

Ulaby, F. T., Moore, R. K., and Fung, A. K.: Microwave Remote Sensing: Active and Passive Volume II: Radar Remote Sensing and Surface Scattering and Emission Theory, Ann Arbor, Artech House., 1982. 
Van den Broeke, M.: Strong surface melting preceded collapse of Antarctic Peninsula ice shelf, Geophys. Res. Lett., 32, L12815, doi:10.1029/2005g1023247, 2005.

Van den Broeke, M., Bus, C., Ettema, J., and Smeets, P.: Temperature thresholds for degree-day modelling of Greenland ice sheet melt rates, Geophys. Res. Lett., 37, L18501, doi:10.1029/2010g1044123, 2010.

Vaughan, D. G.: Recent trends in melting conditions on the Antarctic Peninsula and their implications for ice-sheet mass balance and sea level, Arct. Antarct. Alp. Res., 38, 147-152, doi:10.1657/1523-0430(2006)038[0147:rtimco]2.0.co;2, 2006.

Wang, L. and Yu, J.: Spatiotemporal Segmentation of Spaceborne Passive Microwave Data for Change Detection, IEEE Geosci. Remote S., 8, 909-913, doi:10.1109/LGRS.2011.2140312, 2011.
Wang, L., Derksen, C., and Brown, R.: Detection of pan-Arctic terrestrial snowmelt from QuikSCAT, 2000-2005, Remote Sens. Environ., 112, 3794-3805, doi:10.1016/j.rse.2008.05.017, 2008.

Weng, H. Y. and Lau, K. M.: Wavelets, Period-doubling, and Time-frequency Localization with Application to Organization of Convection over the Tropical Western Pacific, J. Atmos. Sci., 51, 2523-2541, doi:10.1175/15200469(1994)051<2523:WPDATL>2.0.CO;2, 1994.

Zwally, H. J. and Fiegles, S.: Extent and Duration of Antarctic Surface Melting, J. Glaciol., 40, 463-476, 1994. 